\title{
Diffusion of Technology for Language Challenges in the South African Healthcare Environment
}

Phathutshedzo Makovhololo, Tiko Iyamu*

Department of Information Technology, Faculty of Informatics and Design, Cape Peninsula University of Technology, Cape Town 7700, South Africa

\section{A R T I C L E I N F O}

Article history:

Received: 18 June, 2020

Accepted: 09 July, 2020

Online: 28 July, 2020

Keywords:

Healthcare

Diffusion of Innovation

Language translation

\begin{abstract}
A B S T R A C T
Even though mobile technologies are increasingly used to enable communications between providers and receivers of healthcare services, there remain severity challenges owing to the use of various indigenous languages in many Africa countries. Some of the challenges get worst in a countries like South Africa where there are eleven official languages. As a result, interpreters and technology-enabled translation become inevitable. However, technology-enabled translation is even more complex because of the semantics that exists in the languages. The study was undertaken to identify the critical challenging factors that exists in the use of South African languages for healthcare services. The interpretivist approach was employed, and Rogers' diffusion of innovations (DOI) theory was applied in the analysis of the data, to examine and understand how indigenous languages affects healthcare services. From the analysis, six factors were found: confidentiality, translation, interpretation, synchronisation, spoken language, and integration, and categorised into three groups, namely ethics, services and systems.
\end{abstract}

\section{Introduction}

The activities and care of the health sector include diagnosis, medications, and treatment of disease and other forms of illness [1]. These activities rely on communication between actors (patients and healthcare practitioners) in the providing and receiving of healthcare services. As a result of significance of communication, information and communication technology (ICT) solutions, such as mobile technologies are explored as enabler. The ICT solutions are increasingly being used to facilitate communication of information across healthcare teams and groups, in the delivering of care and services [2]. Despite the increasing use of technology-enabled communication solutions, there remain many challenges. Some of the challenges arise from the use of various languages and dialect, which has different semantics. This challenge is worst in South Africa where there are eleven official languages.

Overcoming language barriers within the healthcare sector is considered one of the critical challenges threatening care services to patients [3]. At the time of this study, there were about 54 million people in South Africa. From which only 4.9 million people were English speakers, and the remainder of the population speak African languages such as IsiZulu, IsiXhosa, Sepedi, Sesotho, Tshivenda, and Xitsonga. Consequently, the healthcare

${ }^{*}$ Corresponding Author:Tiko Iyamu, Email: connectvilla@yahoo.com delivery system is hard-pressed to handle this diversity [4]. Qassim gives an example, that when capturing text using two different languages for the same thing, translation is required because different meanings can be created despite similarities in the intentions to say the same thing [5]. Another factor that influence the challenges of communication is cultural affiliation. In addressing some of these challenges, innovations can be employed and diffused. Rogers diffusion of innovation (DOI) has been applied in my studies where innovations or diffusion of technologies were investigated [6].

The DOI theory has been widely applied in studies including those of public health and medical care, in many areas such as diffusion, integration, innovation, and implementation [7]. In DOI, an innovation is referred to as "an idea, practice, or object that is perceived as new by an individual or another unit of adoption" [6: 11]. Diffusion is defined as "the process by which an innovation is communicated through certain channels over time among the members of a social system" [6]. One of the focuses of the DOI theory is to understand why "potential users make decisions to adopt or reject an innovation based on beliefs that they form about the innovation" [8]. Theories are concerned with the manner in which a new technological idea, artefact or technique is migrated from creation to use [9]. Rogers classifies the innovation-decision process into five categories: (1) knowledge; (2) persuasion; (3) decision; (4) implementation; and (5) confirmation [6]. 
Based on the discussion presented above, the objective of this study was to identify the factors that critically influence healthcare services in the use of South African languages. The remainder of this paper is structured into 5 main sections as follows: the literature review is followed by the research methodology. Thereafter, the analysis of the data, and the discussion of the findings are presented respectively. Finally, the conclusion is drawn.

\section{Literature Review}

The use of language enable and at the same time constraint communications and interactions in some instances. In South Africa, there are eleven official languages, which include English and indigenous languages. Of the languages, English is the most used as a medium of communication, which is a challenge for the majority who are neither literate nor fluent in the language [10]. This is a challenge that affects medical services in the country, which have more negative impact on patients' health conditions [11], [12]. For examples, some doctors' over-treat patients as result of limited English proficiency, resulting from lack of appropriate self-expression of health condition, and some patients are referred to get unwarranted additional tests and procedures [13], [14]. Language barrier is not only about proficiency, but complicated by semantics, which is often unique in translation. Translation of semantics in languages tend to be a more complex, awkward, detailed, and concentrated thought-process [15].

Based on challenges posed by language, ICT solutions such as mobile systems has been employed to accelerate access, and provide a wider range of health services in order to enhance the well-being of underprivileged people in South Africa [16]. Also, translation of semantics in some languages often change the original meaning that was associated with certain words [17], which has made it difficult for mobile systems to address. Healthcare service providers have increasingly employed mobile systems in delivering services [18].
Due to sensitivity of some health conditions, many patients prefer to be active participant in their own care by communicating directly with the practitioners, to influence decisions relating to their own care [19]. This includes accessing of information using language of their origins. This potentially improves communication between individuals and healthcare providers, ICT systems such as personal health records (PHR), which ultimately increases patients' participation in healthcare. Some ICT systems can be used to engage with patients toward improving communication [20]. The challenges posed by language affect integration of information systems, and access to health information.

Misunderstand between patients and health practitioners can result to fatality. An example is a case of 'Life Isidimeni' in South Africa where many patients lost their lives owing to distortion in communication, and other factors [21]. This once again demonstrates that the limits of language are the limits of a person's world, and the fact of the matter is that the 'real world' is to a large extent unconsciously built upon the language habits of the different communities of humans, speaking different languages. Different groups think differently to the extent that their languages differ from one another [22]. One of the challenges to be confronted by the healthcare industry is semantic interoperability. Semantic interoperability is the ability of a healthcare system to share information and have that information properly interpreted by the receiving system in the same sense as intended by the transmitting system. Semantic Web provides enabling technologies to achieving semantic interoperability [23].

\section{Prepare Your Paper before Styling}

Based on the objectives of the study, the interpretivist approach and qualitative methods were employed. Vosloo states that the interpretive approach enables access to reality through language and shared meanings [24]. The approach was employed in this study to seek explanation within the realm of individual consciousness and subjectivity, and within the socially constructed sphere of human relations [25]. This was done within the context of case study.

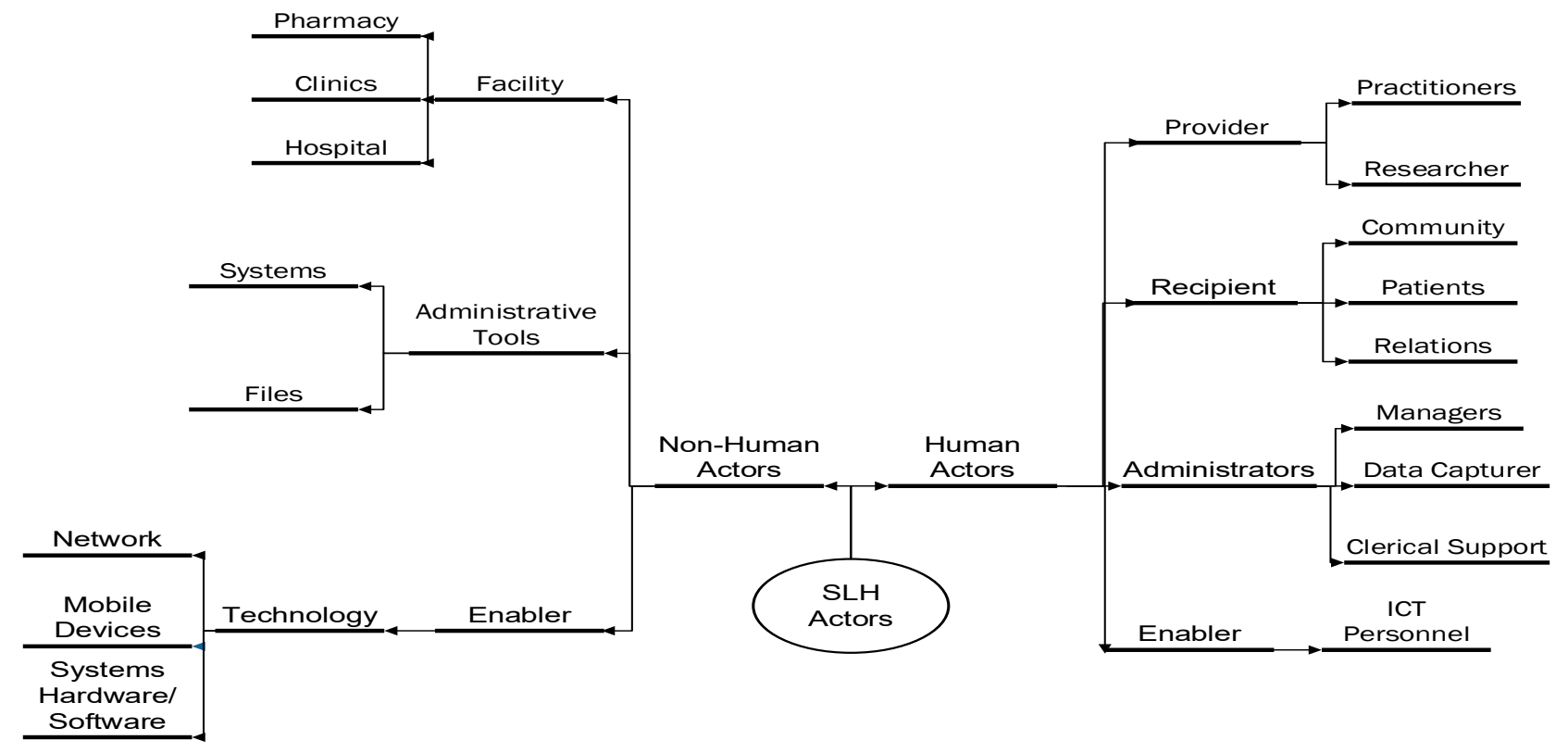

Sweet Love Hospital human and non-human actors 
The case study approach allows focus on specific setting or environment, and multiple sources of evidence [26]. With the approach, it is also easier to extract cultural knowledge, identify actions and instruments that participants utilise in their everyday life in an organisation [27]. A health facility with the pseudo name 'Sweet Love Hospital' (SLH) was selected. The facility renders health services to all that lives in South Africa, irrespective of beliefs, cultures, and spoken language. Human and non-human actors in SLH were categorised into four phases, as shown in Figure 1: (1) provider, (2) recipient, (3) administrator, and (4) enabler. The facility is situated in Pretoria area of South Africa. The hospital focuses on patients who have been diagnosed of chronic conditions, such as tuberculosis, Human Immunodeficiency Virus (HIV), and cancer. In providing healthcare services to the patients, require regular and constant communication is vital. However, the patients are diverse in spoken languages, which sometimes affect the type of services that they receive.

The semi-structured interview was applied to gather data. This helps to gain an understanding about behaviours, beliefs, opinions, emotions, and relationships between individuals and groups [28]. The primary purpose of conducting interviews is to gain an understanding of the meaning of what the interviewees say. Participants in the study were from different unit of the hospital, which included medical practitioners (nurses and doctors), IT and administrative services. A total of eleven people were interviewed at the point of saturation. The interviewees were labelled 'SLH01 to SLH11' in order to preserve their identities.

The analysis of this data followed the interpretivist approach, which was guided by [6] Diffusion of Innovation (DOI). The use of DOI theory focuses on how decisions were made by both healthcare providers and recipients on languages preferences for health services. The DOI helps to explain how, over time, an idea or product gains momentum, and diffuses through a specific population or social system [29]. According to Striphas an innovation can be an idea, knowledge, a belief or social norm, a product or services, a technology or process, even a culture, as long as it is perceived as being new [30]. For Rogers, the innovationdecision process involves five steps: (1) knowledge, (2) persuasion, (3) decision, (4) implementation, and (5) confirmation [31]. These stages typically follow each other in a time-ordered manner, as applied in this study.

\section{Data Analysis}

\subsection{Innovation decision process: Knowledge}

The innovation-decision process starts with the knowledge, a stage where individuals learn about the existence of innovation, and seek information concerning the innovation. "What?" "How?" and "Why?" are critical questions at the knowledge stage. Also, during this stage, an individual attempts to determine "what the innovation is and how and why it works" [31]. According to Rogers, the questions form three types of knowledge: (1) awareness-knowledge, (2) how-to-knowledge, and (3) principlesknowledge.

Some health practitioners in SLH make use of IT solutions such as mobile system to access information, and engage in communicate with colleagues and patients. However, it becomes challenging for IT staff when some health practitioners (users) are not able to make use of the system appropriately. According to
SLH01 (2:66-67), "sometimes, it is a challenge when users are not knowledgeable about the application of technology". The emerging and changing technological development has led to a rethinking in the way technology can be effectively used in the delivering of healthcare. Technology-enabled systems allow healthcare providers to deliver better support at lower cost as well as contribute to quality health services. Therefore, healthcare practitioners must have a thorough knowledge of how different technologies in their environment work.

Technology certainly plays a part in the success or failure of these operations in SLH. Without a robust IT infrastructure, SLH would not be able to deliver the promised benefits of integration. This may not be immediately obvious to people in the healthcare industry, which were near the bottom of the ladder in terms of IT spending and uniform data standards. "Some employees were aware of the technology and any software application that can make their tasks including communication easier" (SLH01, 2:7273 ). The SLH was challenges with language which was being used to communicate because not everyone in South Africa are able to speak all eleven official languages of the country. Furthermore, many people are not literate or knowledgeable enough to be able to assimilate communications understandingly. According to SLH03 (9:344-345), "we send messages to the patients in our own languages, and we don't get feedback, which is because some of the patients do not understand the language that we are trying to communicate with".

The SLH has many stakeholders, each with an agenda. Often these players have substantial resources and the power to influence public policy and opinion by helping or hindering an innovator. For example, hospitals and doctors sometimes end up blaming technology-driven product innovators for the healthcare system's high costs because they lack the knowledge of what has caused the problem. "They hardly acknowledge that they do not know how to use the application" (SLH02, 5:180). Also, many SLH clinics are situated in remote villages lacking easy access to hospitals and advanced medical facilities. However, the village inhabitants are now being educated through telemedicine and digitalised health information. This initiative is helping millions of citizens to improve their daily lives. This will address the knowledge and skill transfer of how to use mobile systems.

As medical technology evolves, the determination of how and when to adopt or invest in this technology increases in importance. Move too early, and the infrastructure needed to support the innovation may not yet be in place; wait too long, most of the SLH users are not using the technologies available them because they are not fully aware of them. While some are aware, they often lack the knowledge of language semantics used as part of the application. "We try to understand why some of the patients did not respond, and you find out that the problem was about language. Some of them did not understand what we have sent to them" (SLH01, 6:233-234).

\subsection{Innovation decision process: Persuasion}

The persuasion step occurs when an individual possesses an attitude, negative or positive, toward the innovation. [31] describes this as "the formation of a favourable or unfavourable attitude toward an innovation does not always lead directly or indirectly to an adoption or rejection". The individual shapes his attitude after learning about the innovation, so the persuasion stage follows the knowledge stage in the innovation-decision process. As in many African countries, most adults, aged 55 and above in SLH did not 
find the use of technology friendly, which affect their use in accessing healthcare. The impact is not only from the use of technology but also the language that is used as part of these technologies. People, therefore, are more inclined to recognise ICT usefulness in healthcare, especially if they have had exposure to the systems.

The management of SLH resorted to awareness campaigns, through which they educated elderly patients on the use of technology in accessing health information. According to SLH03 (9:332-333), "we always educate the users, and try to make them understand the benefits of using technology such as the pharmacy automation system for healthcare services". At SLH it was definitely challenging to persuade the user to accept systems before they could visibly see the functionality; some were persuaded while others waited for full implementation. For example, "the pharmacists accept the use of the 'mega four' system. It was only then it occurs to many of the patients how important or beneficial it is to buy-in, and use the system" (SLH03, 9:332-333). Persuasion becomes difficult because a number of patients are illiterate, escalating the difficulties which many healthcare providers endure. Furthermore, [31] states that while the knowledge stage is more cognitive (or knowing) centred, the persuasion stage is more affective (or feeling) centred. Thus, the individual is involved more sensitively with the innovation at the persuasion stage. This was revealed at SLH: those in the same unit, communicated better, and interaction got easier.

The degree of uncertainty about an innovation's functioning, and the social reinforcement from others (colleagues and peers, for instance) affect individuals' opinions and beliefs about the innovation, to an extent that IT personnel have to devise ways of making the users understand how this innovation works. According to SLH01 (4-5:160-162), “As times goes by, as you deal with these challenges, you learn better ways of explaining things to the users at their level of knowledge". In most instances, communication about the innovation is silent which affect awareness and knowledgeability. As a result, many health practitioners as well as patients were not able to make use of some of the available systems

This was despite the fact that technologies were required, they were also barrier during interactions between healthcare workers and patients in providing or receiving healthcare service. If healthcare service providers were educated enough on the use of technologies, it had been easier to convince them to adopt the technology, so as to avoid the need for a third party. A third party as interpreter compromises privacy and confidentiality, which in turn affects the ethics code of conduct. Therefore, it is important to develop technologies that can translate and interpret for patients rather than the use of a person as a third party. One of the participants, SLH04 (10:406-407) expressed her view as follow: "The communication team that always translate the messages into vernacular or indigenous languages were not always professional interpreters or translators". This demoralises some patients because information about their health was not treated with confidentiality.

\subsection{Innovation decision process: Decision}

It is at the decision stage of the innovation-decision process an individual can choose to adopt or reject the innovation. While adoption refers to "full use of an innovation as the best course of action available," rejection means "not to adopt an innovation" [31]. If an innovation has a partial trial basis, it is usually adopted more quickly, as most individuals first want to try the innovation in their personal situation before arriving at an adoption decision. Healthcare providers in SLH were faced with a number of challenges, which included the increasing size of the aging population, shortage of healthcare workers, patients' demands for increased access to health information, and participation in healthcare related decision-making, and rising healthcare costs. According to SLH03 (9:333-335), "it was very challenging for the pharmacists to accept the 'mega four', when the system was initially deployed and introduced". The vicarious trial can speed up the innovation-decision process.

However, rejection is possible in every stage of the innovationdecision process. Most of the doctors were satisfied with adapting, as they want advance ways to lighten or hasten their jobs, but the nurses find it difficult as they were used to old ways of manual systems. Many people remain loyal with their old approach, but with time, they will become accustomed to new ways. In an attempts to increase productivity, some healthcare leaders and decision-makers tend to focus on short-term financial gains. However, the short-term gains derived from rash and quick decisions to solve a big problem can result in communication breakdowns that produce higher overall healthcare costs, such as inaccurate diagnoses that prompt unnecessary tests and services repeated multiple times. As per SLH11 (32:1269-1271), “Across the sphere of South Africa, we work directly with healthcare practitioners and government representatives, to identify facilities, sub-districts, districts and provinces where we can deploy unique models in addressing individual and group needs".

Dealing with technologies can incur heavy financial challenges. There are times when decisions are made to rely on their own staff as interpreters forced by circumstances they found themselves in. They don't have full-time interpreters on the premises, so if they need a professional interpreter, they must request this from public hospitals for assistance, which cause critical delays. However, these providers fail to consider both the consequences of not providing the services and the potential cost benefits of improving communication with their patients. Sometimes, they claim the challenge rests not necessarily with the language per say, but on the terminology used on the devices that are provided. According to SLH04 (12:454-455), "I think the issue of semantics is, one of the challenges, which also depends on the kind of messages that you try to send to the patients". The SLH attempts to address the issue of language semantics translation, which requires decision and implementation of the decision that has been made.

\subsection{Innovation decision process: Implementation}

At the implementation stage, an innovation is put into practice. However, an innovation brings the newness in which some degree of uncertainty is involved in diffusion. Uncertainty about the outcomes of an innovation can still be a problem at this stage. Thus, the implementer may need technical assistance from change agents and others to reduce the degree of uncertainty surrounding the consequences. At the time of this study, SLH has partnered with the Department of Health of the country, purposely to eradicate the uncertainty of users: "from working with the Department of Health and our global donors, we have secured funding to rollout the e-Pharmacy system, which have helped in our health-related activities" (SLH08, 27:1096-1097). Moreover, the innovation-decision process will end, since "the innovation loses its distinctive quality as the separate identity of the new idea disappears" [31]. 
The use of ICT solutions in the SLH healthcare sector has wellknown advantages: promoting patient-centred healthcare, improving quality of care, and educating both health professionals and patients. However, implementation of ICT solutions remain difficult as it involves changes at a variety of levels: patients, healthcare providers, and healthcare organisations. In order for SLH's IT Department to achieve their goal of implementing these technologies, they require the support of the users, who in this case were healthcare practitioners (physicians, nurses, councillors, researchers, fieldworkers, pharmacists, administrators, and executives). The experience of difficulty in communication or language in many instances, IT personnel proactively demonstrated interest by accommodating the users as they interact with them. The implementation of computer-aided detection of Tuberculosis at SLH, was an example that radiologists were scarce in South Africa, and to review each digital x-ray would have been time-consuming and costly. The facility, SLH searched for available technologies being used abroad towards addressing this challenge: "We selected a Computer-aided detection for Tuberculosis (CAD4TB ${ }^{\mathrm{TM})}$ that was developed by Delft Imaging Systems. The system was designed to help (non) experts' readers in the diagnosis of TB" (SLH02, 28:1138-1139).

In SLH, the implementation of mobile health was a significant challenge in that it was attributed to the broad scope of services that mobile health need to address. This includes lack of resources such as infrastructure; and a lack of funds. In 2014, SLH identified the need to methodically document, evaluate, and share best practices, clinical principles, and innovations arising from the organisation's programmes. The organisation established a dedicated operational research unit to meet these needs. Many of the unit's solutions have resulted in significant positive changes to clinic functioning and consequently in the lives of patients. The health facility, SLH managed to implement systems such as "an interface between TherapyEdge ${ }^{\circledR}$ and Trimed $\AA$, to eliminate the need for pharmacists' to recapture prescriptions' data" (SLH07, 25:1020-1021). From the implementation, the transfer of data was managed via SHL07 messaging (an industry standard messaging system). This ensures up-to-date flow of patients' demographic and prescription data between the systems, each system receiving and sending real-time information.

The innovation-decision has already been made, but at the confirmation stage an individual seeks support for his or her decision. According to [31], this decision can be reversed if the individual is "exposed to conflicting messages about the innovation" (189). However, the individual tends to stay away from these messages, and seeks supportive messages that confirm his or her decision. Thus, attitudes become more crucial at the confirmation stage. In this case, SLH accepted the innovation: "The response was very positive. The e-Pharmacy dispensing unit made our lives easier because we no longer do somethings manual, such as standing in long queues and working long hours" (SLH03: 338-340).

An efficient user-friendly customer relationship management (CRM) application was used to speeds up efficiency of wellness and HIV testing. The LoveHealth Mobile enables staff members to seamlessly synchronise data from a central database with mobile data capture devices. These systems enable testing process, while capturing accurate test information. One of the participants (SLH06, 22:929-931) explained: "it can also save time and at the same time, it limits invasion of privacy, which makes some people feel free to express themselves without third party".

www.astesj.com
Finally, the widespread adoption of mobile technologies at SLH allowed for system connectivity and information exchange between practitioners, healthcare organisations, and ultimately between patients and community. However, the actual realisation of these benefits depended on how SLH implements and deploys the mobile technologies. As results were dependent on the support for adoption of the innovation and the attitude of the individual, later adoption or discontinuance happens during this stage. External suppliers with similar trucks were contracted and the digital x-rays routed into the same central Picture Archiving Communication System (PACS) for review and reporting. This innovation has empowered SLH, in partnership with LoveHealth, to x-ray 57290 Department of Correctional staff and inmates. According to SLH07 (29:1157), "after the success of the first truck, two more were built and rolled out".

\section{Discussion of Findings}

Based on the analysis of the data, six critical factors were identified for the translation of semantics in languages in providing and receiving healthcare services in South Africa. As shown in Figure 2, the factors - confidentiality, translation, interpretation, synchronisation, spoken language and integration - were categorised into three groups, namely ethics, services, and systems. The groupings were subjectively reached, based on the closeness of the factors in the provision and receipts of healthcare services. The three groupings are discussed below.

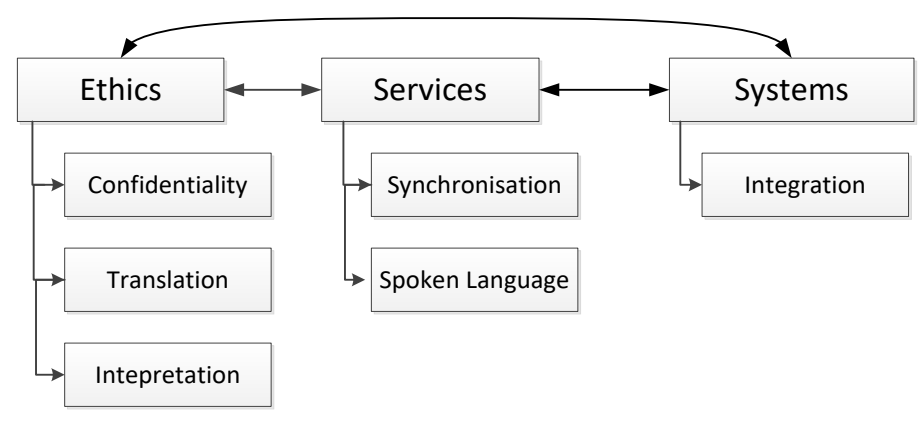

Factors that influences technology diffusion.

\subsection{Ethics of health information}

Healthcare practitioners are governed by code of conduct, which include keeping patients' information private and confidential. This was critical to the hospital since it focuses on chronic conditions which include HIV/AIDS and tuberculosis. In the provision and receipt of service for these and other chronic conditions and the general healthcare, ethics are required to guide the activities of translation of semantics in languages. Chronic conditions are considered very sensitive, for a host of apparent reasons. Thus, confidentiality was high in the ethical code of conduct of the SLH. In addition, translation and interpretation were critical from the viewpoint of semantics, which must prioritise ethical behaviour. These factors - confidentiality, translation and interpretation - were challenging for both patients and healthcare practitioners owing to their inseparability nature.

Due to these challenges, compounded by lack of knowledge of the practitioners, some of the health practitioners began to form different groupings (networks), along spoken languages and area of specialisations. These networks were formed with the intention 261 
of addressing practitioners and patients' communication barriers. Some practitioners tapped on actors in their networks as resource to play the of interpreters of semantics that they themselves were unable to translate in some of the languages. Lack of knowledge about some spoken language led to making decisions, which became norm and culture of the hospital, irrespective of the fact that this culture or norm was unethical, in that the informal interpreters were not trained to do so. As a result, some of the interpreters did not have deep enough understanding of the languages to carry out semantics translation. Translation of semantics in languages requires a precise standard that can be followed for accuracy of meanings. For example, as expressed by one of the nurses, in Tshivenda, "Ndi tshitamba tshifhinga tshothe nowa yanga iya luma", which means "I suffer from period pain every time I menstruate". But when translated into English, it means "every time I take a bath my snake bites".

There were inaccuracies in translations of semantics in some of the languages. As a result, patients' levels of trust and confidence in the healthcare practitioners began to drop, and some patients involved their family members or friends to help with translation during consultations with health practitioners. This approach breaches practitioner-to-patient confidentiality, which compromises ethical behaviour. Also, there was no proper documentation on how translation was carried out at the SLH. This could have informed the creation of a repository, where reuse of translation can be enabled for accuracy and consistency purposes.

The fear of information leakage, sometimes caused some patients to lie about their actual health conditions, which often resulted to wrong diagnoses and medications. The code of conduct doesn't only apply to healthcare practitioners, but also to patients who need to be knowledgeable of ethical practices and behaviours on health matters. There is a clear need for education and awareness for practitioners concerning the issues of the code of conduct. This will minimise legal suits and prevent loss of lives, which result from misconducts.

\subsubsection{Confidentiality}

The SLH employs a dual confidentiality approach in accessing information, and interaction between healthcare practitioners and patients. However, the involvement of a translator, a third party, weakens this approach, and makes the goal of confidentiality less achievable. But all hopes are not lost as the use of a mobile system for translation of semantics in languages can reinforce security and privacy of information. The mobile system solution for semantics translation can instil trust and confidence in both practitioners and the patients. Thus, patients do not have to choose which practitioners they need to consult with because they were scared that privacy is at risk.

From two main perspectives, the mobile systems solution can be of critical importance for confidentiality in the translations of semantics, as follows: (1) the solution enables and support reuse, which can be efficient in the storage and retrieval of translated semantics in the languages that are prevalent for communication at $\mathrm{SLH}$; and (2) the mobile system solution allows for validation of information at various levels, and grants various levels of access to information to both practitioners and patients. This improves manageability and confidentiality of patients' information. Also, this approach enhances compliance to health ethics within SLH. Most importantly, the mobile system solution approach can improve health service delivery.

\subsubsection{Translation}

Translation of healthcare terminology in any language, especially South African languages, can be very difficult to virtually impossible. As revealed in the analysis, many meanings get lost in translation from English to some South African languages such as Tshivenda, Sepedi, Xitsonga, and IsiZulu. Even so, community members and patients were faced with the challenges of having to translate these words at critical times in their life. For example, if an Xitonga-speaking patient says to the health practitioner at SLH: "ndzi twa ndzi hlamba timbilu", the English translation means "I feel like my hearts are washing". However, what the patient was trying to say is that "I feel nauseous".

More often than not, patients and community members source health-related information from media such as radios, television, and the internet. Some of the information gets confusing instead of providing clarity to gain an understanding of health conditions. The confusion is often caused by challenges in attempts to directly translate certain words and phrases from English to the indigenous languages. In some cases, in attempts to address the confusion, networks of interested members are unconsciously formed. Despite the efforts, accurate meanings of some words were not realised because of semantics. Thus, the closest of meanings are accepted, sometimes based on assumptions, as language translation of semantics is sometimes based on assumptions and the little knowledge some members of the network have. This challenge is mostly with illiterate patients.

Those had advantage were mostly the literate patients or relations of illiterate patients who further carry out searches on relevant topics and hope for better translation through translationtriangulation: (1) accurate translation to a language such as Sepedi; (2) thereafter, translation from Sepedi to Xitsonga; and (3) double checking a word's meaning in English. However, the triangular approach does not necessarily accurately resolve the problem, for two main reasons: (1) it is not common to have interpreters who are deeply fluent in two or more South African languages; and (2) some semantics do not exist in or cannot be translated to other languages. Wrong or inaccurate translations can be dangerous in that it leads to wrong medical decisions that can seriously impact patient's health in the long run or fail to prevent an illness that could have been otherwise prevented.

\subsubsection{Interpretation}

Within healthcare ethics, interpretation of semantics in languages is vitally important, especially during consultation with patients. As a result, either the patients or practitioners get an interpreter if they realise that there is a communication challenge. Although this often solves the immediate problem, it is unethical for healthcare practitioners or patients to randomly choose an interpreter. Also, it is ethically wrong for healthcare practitioners to allow themselves to be influenced by a patient, to make use of their next of kin as an interpreter. This is mainly because it is highly unlikely that non-professional interpreters will adhere to 
health ethics code of conduct. The non-professional interpreters do not sign the ethic code of conduct, also do not understand the details and implications of breaching the code of ethics within the sensitive health environment. In addition, there is no guarantee that non-professional interpreters will be accurate in their interpretation of semantics in some languages.

Owing to this challenge, some of the things patients had to say or tried to explain might be 'lost in translation' in that some semantics in some languages cannot be easily translated. Despite the risk of miscommunication, there is no standard method of translating semantics of languages. The depth of some of the languages do not help in addressing translation challenges. Also, in some instances, the interpreters were not appropriately trained to understand the semantics in the languages. Due to lack of knowledge and faulty understanding of the semantics in language, the words lose meanings. This may impact patients who are illiterate as they won't know the difference. If these patients were literate, they may not have even needed an interpreter in the first place. Therefore, in this respect we have two issues: translating what someone does not have acute knowledge of, and violation of the code of conduct.

\subsection{Providing health services}

The health services rendered by the hospital have to be of high quality irrespective of the patients' spoken languages, cultural or religious affiliations and background. Therefore, the intended quality should determine the innovations that the hospital employs. Providing healthcare services require collaboration among health practitioners, in their use of patient information, technologies and innovations. However, collaboration was not always synonymous to service at SLH. Some practitioners relied solely on their individual knowledge of an incident or wealth of experience. Through their stock of knowledge and wealth of experience, they made decisions to create an innovative approach. This impacts the services being rendered by the hospital as a whole. The danger was that some of those innovative approaches were not validated. The use of a mobile system can help address this challenge, in that the knowledge and experiences can be documented in a repository which can be accessed at any time and for various purposes by the practitioners.

The innovations for health services were embedded with terms (semantics) that were only understandable by the creator. This was another difficulty that both the creator of the innovation and the interested parties (other health practitioners) encountered. The challenge can be attributed to the main reason why the creators of the innovation had rather chose to make it exclusive. However, if they could communicate and enlighten other colleagues of the innovations, they had persuaded more interested persons in the adoption of the innovation. Duplication of services costs valuable hospital resources and time as people have to redo what has been done but in a different format. This might also have an impact on the use of technologies as each comes with its own terminologies. However, the hospital must be able to use the same terminology to avoid being lost in translation as some patients and health workers might not be able to understand the semantics in those systems of which they are unaware.

\subsubsection{Synchronisation}

Taking ethics into considerations, synchronisation is critical within the healthcare environment, primarily because it is experimental-based. Some healthcare practitioners, particularly doctors, bring into their practice what they think is the best innovation according to their knowledge without considering what is already available. For example, only one of the doctors at SLH made use of an open source system, to communicate with pregnant women who were on chronic medications. Some health practitioners sometimes do this without following any stringent process, which often affects an existing process. Such approach began to affect developmental processes, and knowledge sharing within the environment. If they had followed a process, they would have been able to persuade employees through relevant training on the use and application of the innovation. Then one particular system would have then be enhanced, if need be; however, with this process they end up with two systems which were not integrated, but running in parallel.

\subsubsection{Spoken language}

As revealed from the data analysis, spoken language was key to provision and receipts of healthcare by SLH and patients, respectively. At the time of this study, SLH did not have a system to identify the areas as per different spoken languages. Therefore, such identifications were done by guesswork. As a result, practitioners were allocated to areas for health services based on their availability, not based on whether they can communicate in the predominant language of the people in the area. The implication of this decision negatively impacted prescriptions, medications, and medical guidance provided to some patients. Some healthcare practitioners were not knowledgeable enough to make the responsible decision that they made when they sent practitioners out to the field. They sent people based on guesswork, availability of personnel, which were insufficient requirements for such sensitive environment.

\subsection{ICT Systems for health services}

At the SLH, there were various ICT systems. The use of systems did improve healthcare services to patients. However, the specialists were required to have a deep knowledge of the available systems before embarking on the implementation process. This was not always the case at SLH as some specialists lacked knowledge of the systems they intend to implement. As a result, groups of practitioners tried to find for themselves systems that worked best. Thus, some of the systems were implemented in isolation, without communicating or making their colleagues aware of the system's existence.

The implementation of numerous systems without proper valuation led to duplication of systems as well as services, as some practitioners made use of systems in isolation, while other practitioners employed their own systems. The systems then run in parallel without integration. Therefore, patient's information gets duplicated depending on the structure of the system. In some cases, patient's information was not captured appropriately and completely. In emergency cases, this caused frantic delay in trying to identify the patient by using parallel systems. It get worst if the patient's details such surname or address has changed in recent 
times. The dual system was not the main challenge, but the lack of synchronisation, which could have regularly update the patients' details in the systems.

\subsubsection{Integration}

The hospital's systems were not integrated at the time of this study. From the inquiries to the general practitioners and pharmacy, parallel systems were operated. Unfortunately, these systems were not 'talking to each other'. As a result, some patients explored the gaps and often obtained more than one prescriptions. Such situations were not traceable because the systems were not linked. As was revealed from the data analysis, some patients' who live in informal settlement get medications from clinic in their area, and subsequently travel to another clinic to collect again the same medications because their systems cannot detect that the patient has already received this medication.

This practice by some patients to take advantage of the gap, lack of integration between the systems was influenced by two main reasons: (1) some of the patients sell the extra medicines to friends and interested persons; and (2) others consume more medicines than the prescribed doses. As for the latter, some of the patients held the erroneous belief that the more medicines they consume, the quicker they get healed. Another implication for the hospital (SLH) and its clinics was that they were often running short of medications. Shortage of medications led to fatalities as people were dying because of shortages in the supply of medications. These challenges were yet more devastations caused by inaccurate translation of languages or the semantics in languages.

The fact that the parallel systems were not in sync has led to poor performance of some of the staff members as they find themselves having to perform certain tasks repeatedly. The data capturing was hard-pressed with capturing of patients' information that came from the doctors and pharmacies. If the systems were integrated, several of these continuously repeated steps had be eliminated. As it stands, the process takes long, and patients queue for long hours. As revealed in the data analysed, some patients 'passed out' as a result of fatigue, which chronic patients are generally sensitive to. Mobile systems would be the solutions, as they can be used to integrate the parallel systems so that the information can be synchronised for improved efficiency and effectiveness of healthcare services.

\section{Conclusion}

This study identifies and presents some of the factors that influence the challenges some patients and health practitioners encounter in their attempt to communicate in the delivering and receiving services. As shown in Figure 2, the study puts the factors in perspectives as it demonstrates how they interrelate to influence actual communication between patients and health practitioners in the use of different languages. Both government and managers of healthcare services can make use of this study to trace the factors' influence in avoiding the delivering of poor services in the country.

The significant of this study can be viewed from three main perspectives: (1) health practitioners can now be more sensitive to patients' predicaments, based on the identified factors, which some of them didn't know the extent of the challenges; (2) the factors are empirical evidence that can guide policymakers in formulating and promulgating policies for the enhancement of healthcare services; and (3) the factors can guide software developers in developing a system that translates semantics in South African languages, which can be used by both practitioners and patients. From academic front, the study adds to existing literature in the areas of IS, healthcare, and language. Currently, there are very rare literature in the area of IS and healthcare from language translation perspective, particularly in developing countries.

As work continues in improving healthcare service delivery, further studies can focus on measuring the impact of the factors identified in this study. This includes development of mobile systems for the translation of African languages.

\section{Acknowledgment}

The authors wishes to acknowledge and thank the Cape Peninsula University of Technology (CPUT) for giving us an opportunity to explore and grow in the research world.

\section{References}

[1] K. S. Gupta, V. Rokade, Importance of quality in health care sector: A review.

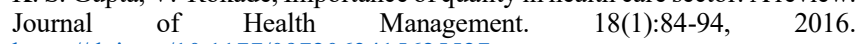
https://doi.org/10.1177/0972063415625527

[2] O. P. Kogeda, N. Mpekoa, Model for A Mobile Phone Voting System for South Africa. $\quad$ In 2013 Conference. https://www.researchgate.net/publication/256815434_Model_for_A_Mobile Phone Voting_System for_South_Africa

[3] S. Naidoo. Transcultural and language barriers to patient care. South African Dental Journal. 69(9):425, 2014. https://hdl.handle.net/10520/EJC160573

[4] L. R. Burns, ed, The business of healthcare innovation. Cambridge University Press, 2012.

[5] A. H. Qassim, Translation, grammatically, viewed. University of Baghdad/College of Languages. 2014.

[6] E. M. Rogers, "Diffusion of Innovations: modifications of a model for telecommunications." In Die diffusion von innovationen in der telekommunikation, 25-38. Springer, Berlin, Heidelberg, 1995. https://doi.org/10.1007/978-3-642-79868-9 2

[7] A. S. Lien, Y. D. Jiang, Integration of diffusion of innovation theory into diabetes care. Journal of diabetes investigation, 8(3), 259-260. https://doi.org/10.1111/jdi.12568

[8] R. Agarwal, Individual acceptance of information technologies. Framing the domains of IT management: Projecting the future through the past, 85-104, 2000.

[9] P. Nemutanzhela, T. Iyamu, "Theory of diffusion of innovation for analysis in information systems studies," 2015 Science and Information Conference (SAI), London, 2015, 603-608, doi: 10.1109/SAI.2015.7237205.

[10] B. K. Daigle, Jr L.G. Kent, W. T. Daniell, W. H. Eason, S. N. Zellner, J. C. Liu, R. A. Koch, "Electronic message translations accompanied by indications of translation." U.S. Patent 8,027,438, issued September 27, 2011.

[11] E. J. Peréz-Stable, A. Nápoles-Springer, J. M. Miramontes, The effects of ethnicity and language on medical outcomes of patients with hypertension or diabetes. Medical care, 35(12), 1212-1219, 1997. doi: 10.1097/00005650199712000-00005.

[12] T. M. Tocher, E. Larson, Quality of diabetes care for non-English-speaking patients. A comparative study. Western Journal of Medicine, 168(6), p.504, 1998. PMID: 1305066.

[13] R. A. David, M. Rhee, The impact of language as a barrier to effective health care in an underserved urban Hispanic community. Mount Sinai Journal of Medicine, 1; 65:393-7, Oct 1998. PMID: 9844369.

[14] P K. Lee, C. N. Rosenberg, H. Tsao, A. J. Sober, Failure of Q-switched ruby laser to eradicate atypical-appearing solar lentigo: report of two cases. Journal of the American Academy of Dermatology, 38(2), 314-317, 1998. https://doi.org/10.1016/S0190-9622(98)70572-9

[15] P. Newmark, A textbook of translation. Vol. 66. New York: Prentice hall, 1988.

[16] N. L. Ruxwana, M. E. Herselman, D. P. Conradie, ICT applications as ehealth solutions in rural healthcare in the Eastern Cape Province of South Africa. Health information management journal. 2010 Mar; 39(1):17-29. https://doi.org/10.1177/183335831003900104 
[17] W. A. Nord, Religion and American education: Rethinking a national dilemma. UNC Press Books, 2014.

[18] C. Free, G. Phillips, L. Galli, L. Watson, L. Felix, P. Edwards, A. Haines, The effectiveness of mobile-health technology-based health behaviour change or disease management interventions for health care consumers: a systematic review. PLoS med, 10(1), e1001362, 2013. https://doi.org/10.1371/journal.pmed.1001362

[19] J. A. Effken, P. Abbott, Health IT-enabled care for underserved rural populations: The role of nursing. Journal of the American Medical Informatics Association. $2009 \mathrm{Jul}$ 1; 16(4):439-45. https://doi.org/10.1197/jamia.M2971

[20] G. M. Fix, T. P. Hogan, D. J. Amante, D. K. McInnes, K. M. Nazi, S. R. Simon, "Encouraging patient portal use in the patient-centered medical home: three stakeholder perspectives." Journal of medical Internet research 18, no. 11 (2016). doi:10.2196/jmir.6488

[21] A. Dhai, The Life Esidimeni tragedy: Moral pathology and an ethical crisis. South African Medical Journal. 108(5):382-5, 2018. DOI: 10.7196/SAMJ.2018.v108i5.13232

[22] L. Gleitman, A. Papafragou, New perspectives on language and thought. The Oxford handbook of thinking and reasoning. 2012; 2:543-68.

[23] S. Iftikhar, A. M. Ishaq, H. F. Ahmad, K. Fatima, "Introducing semantics in DHTs for Grid services in a semantic registry." In 2010 6th International Conference on Emerging Technologies (ICET), 382-387. IEEE, 2010. DOI: 10.1109/ICET.2010.5638457

[24] J. J. Vosloo, A sport management programme for educator training in accordance with the diverse needs of South African schools (Doctoral dissertation), 2014

[25] I. van Zyl, Disciplinary kingdoms: Navigating the politics of research philosophy in the information systems. The Electronic Journal of Information Systems in Developing Countries. 70(1), 1-7 Sep 2015. https://doi.org/10.1002/j.1681-4835.2015.tb00501.x

[26] R. K. Yin, Validity and generalization in future case study evaluations. Evaluation. $2013 \quad$ Jul; 19(3):321-32. https://doi.org/10.1177/1356389013497081

[27] J. Sutton, Z. Austin, Qualitative research: Data collection, analysis, and management. The Canadian journal of hospital pharmacy. 68(3):226, May 2015. doi: 10.4212/cjhp.v68i3.1456

[28] A. Fabijan, H. H. Olsson, J. Bosch, "Customer feedback and data collection techniques in software R\&D: a literature review." In International Conference of Software Business, 139-153. Springer, Cham, 2015. https://doi.org/10.1007/978-3-319-19593-3 12

[29] P. Dutta, Communication of Innovations for Freedom. International Journal of Research in Humanities, Arts and Literature, 2(12), 15-32, 2014. https://www.academia.edu/21193892/_communication_of innovations_for freedom

[30] T. G. Striphas, Communication as...: Perspectives on Theory. Sage; 2006.

[31] E. M. Rogers, Diffusion of innovations. 5th ed. New York: Free Press, 2003. 